\title{
Ocean habitat use in autumn by Chinook salmon in coastal waters of Oregon and California
}

\author{
Jefferson T. Hinke ${ }^{1,2, *}$, George M. Watters ${ }^{2}$, George W. Boehlert ${ }^{3}$, Paul Zedonis ${ }^{4}$ \\ ${ }^{1}$ Joint Institute for Marine and Atmospheric Research, University of Hawaii, 1000 Pope Road, Honolulu, Hawaii 96882, USA \\ ${ }^{2}$ NOAA Fisheries, Pacific Fisheries Environmental Laboratory, 1352 Lighthouse Ave, Pacific Grove, California 93950, USA \\ ${ }^{3}$ Hatfield Marine Science Center, Oregon State University, 2030 S.E. Marine Science Dr, Newport, Oregon 97365, USA \\ ${ }^{4}$ US Fish and Wildlife Service, 1655 Heindon Road, Arcata, California 95521, USA
}

\begin{abstract}
Describing the ocean habitats used by Chinook salmon Oncorhynchus tshawytscha is an important step towards understanding how environmental conditions influence their population dynamics. We used data from archival tags that recorded time, temperature and pressure (depth) to define the coastal habitats used by Chinook near Oregon and California during the autumns of 2000, 2002 and 2003. We used a clustering algorithm to summarize the data set from each year and identified 4 general habitats that described the set of ocean conditions used by Chinook. The 4 habitats, defined primarily by depth and the time of day that these depths were occupied, were characterized as (1) shallow day, (2) shallow night, (3) deep and (4) deepest. The definitions and use of each habitat were similar across years and the thermal characteristics of all habitats included water temperatures between 9 and $12^{\circ} \mathrm{C}$. This temperature range provided the best indicator of Chinook habitat in the coastal ocean. Chinook used 9 to $12^{\circ} \mathrm{C}$ water at least $52 \%$ of the time. Less than $10 \%$ of surface waters within the area where Chinook were released and recovered provided these temperatures. Cross sections of subsurface temperatures suggest that between 25 and $37 \%$ of the coastal water column was available to Chinook and contained water in the 9 to $12^{\circ} \mathrm{C}$ range. These results support hypotheses that link salmon-population dynamics to ocean temperatures. Continued monitoring of surface and subsurface thermal habitats may be useful for assessing the extent and quality of conditions most likely to sustain Chinook salmon populations.
\end{abstract}

KEY WORDS: Chinook salmon · Archival tag · California current - Essential fish habitat Resale or republication not permitted without written consent of the publisher

\section{INTRODUCTION}

It is increasingly understood that both freshwater and marine habitats are critical to the maintenance of healthy Pacific salmon Oncorhynchus spp. populations. Understanding the linkages between environmental conditions, ocean habitats, survival and growth of these fishes is a primary goal of current salmon research initiatives (Boehlert 1997, Gargett 1997, Bisbal \& McConnaha 1998, Welch et al. 2003). Correlations of environmental conditions with catches (Mantua et al. 1997) and production (Beamish et al. 1997, Cole 2000, Hobday \& Boehlert 2001) have demonstrated a strong coupling of oceanographic variability and salmon population dynamics. In particular, temperatures are correlated with salmon survival throughout much of the Pacific Ocean (Mantua et al. 1997, Cole 2000, Mueter et al. 2002a). The effects of environmental conditions on population dynamics, however, are realized through the continuous interactions of individuals with their environment. Unfortunately, individual patterns of habitat use over time and the environmental conditions experienced in those habitats have rarely been measured.

Recognition of the importance of marine habitats for survival and production has fostered research aimed at identifying the environments that salmon actually experience (Boehlert 1997, Welch et al. 2003). Such 
research is important because most studies relating ocean conditions to salmon production are largely inferential; workers have generally been limited to describing environmental conditions at times and places where salmon are expected to occur. Descriptions of the environmental conditions used by salmon in the coastal ocean may help refine the hypotheses that link salmon population dynamics to a variable ocean environment.

The anadromous life history of Chinook salmon Oncorhynchus tshawytscha includes a period of ocean residence that can last from 6 mo to 6 yr (Pearcy 1992). Historical evidence from fishery landings and research surveys has helped to identify broad geographic ranges, depth distributions and temperature associations of Chinook (e.g. Healey 1991, Orsi \& Wertheimer 1995, Welch et al. 1995, Myers et al. 1996) but the evidence for actual habitat use during ocean-residence remains largely inferential. As environmental conditions in the coastal ocean change on several time and space scales (e.g. Lynn et al. 2003), it is likely that the suitability of coastal habitats for growth and maturation are highly variable, especially in any one geographic location. Identification of the ocean habitats that are consistently used by multiple individuals across years should help to better define those habitats that are essential and begin to shed light on how the availability of suitable habitats can change through time.

Recent advances in tagging technologies have improved the ability to measure the dynamic environments used by marine fishes. Previous studies with telemetric and data-storage tags enabled researchers to describe environmental conditions experienced by salmon and behaviors associated with such habitat use. The descriptions of habitat use that were derived from these studies have helped to infer migratory behaviors (e.g. Candy \& Quinn 1999, Friedland et al. 2001) and served as a basis for comparing habitat use among salmonid species (e.g. Walker et al. 2000). For example, short term $(<4$ d) ultrasonic telemetry studies with pressure-sensitive tags on Chinook in the coastal waters of British Columbia (Candy \& Quinn 1999) and in the central Bering Sea (Ogura \& Ishida 1995) discerned diurnal differences in depth use and showed that Chinook consistently used deeper habitats than other salmon species. Temperature recording data storage tags successfully applied to salmonids in the north Pacific (Walker et al. 2000, Friedland et al. 2001) revealed strong fluctuations in temperature use, with a tendency to occupy warmer habitats during the night. To date, we know of no studies that have simultaneously measured both temperature and depth use by Chinook, and compared habitat use across years.

We used temperature-depth data-storage tags to describe the ocean habitats used by Chinook in the coastal waters of southern Oregon and northern California during the autumns of 2000, 2002 and 2003. Our focus is to describe general patterns of habitat use within and between years, and to identify habitats that are commonly used by many individuals. We also compare the temperatures experienced by Chinook to surface and subsurface ocean temperature data to assess the extent and variability of habitat suitable for Chinook in the coastal ocean. Our guiding questions are whether the patterns of habitat use by Chinook are consistent among individuals and across years, and how the availability of that habitat changes through time.

\section{MATERIALS AND METHODS}

We used data from archival tags that recorded time, temperature and pressure (depth) to describe patterns of habitat use by Chinook salmon from the coastal waters of Oregon and California during 2000, 2002 and 2003. The archival tags, Lotek LTD 1100 series $(27 \times$ $16 \times 8 \mathrm{~mm}$ ), weigh $2 \mathrm{~g}$ in water, remain functional to a depth of $1000 \mathrm{~m}$ and are marked with reward and return address information. The tags measure temperature over a range of -5 to $35^{\circ} \mathrm{C}$ with an average resolution of $0.2^{\circ} \mathrm{C}$ and a bias of $<0.3^{\circ} \mathrm{C}$. Depth resolution is $<2 \mathrm{~m}$ with a bias of $<5 \mathrm{~m}$. The interval between successive measurements is adjusted based on the length of time the tag is at liberty. For our data, sample intervals ranged from 1.875 to $30 \mathrm{~min}$. Complete specifications on the tags can be obtained from the manufacturer, Lotek Wireless at www.lotek.com (use of brand name does not imply endorsement by the National Marine Fisheries Service).

During 2000, 2002 and 2003, 175 Chinook were tagged and released. The 15 Chinook used in this study were caught between July and September with hook-and-line fishing gear (using barbless hooks) in coastal waters between Fort Bragg and Eureka, CA, USA. The tags were externally attached to the Chinook (average size $=69 \mathrm{~cm}$ fork length $(\mathrm{FL})$; range $=60$ to $80 \mathrm{~cm} \mathrm{FL}$ ) just ventral to the dorsal fin using a technique, without anaesthesia, as described by Walker et al. (2000). Following tagging, the fish were held in a flow-through enclosure to allow recovery from the tagging procedure and to assess the condition of the fish before release. Usually, no more than 10 min elapsed between the times of capture and release. Tags were recovered from freshwater and marine environments (Fig. 1) by commercial and recreational salmon fishers who then returned the tags to the Pacific Fisheries Environmental Laboratory, at which time the data were downloaded.

We restricted our analyses to the marine portions of the data during autumn. We chose this relatively short 


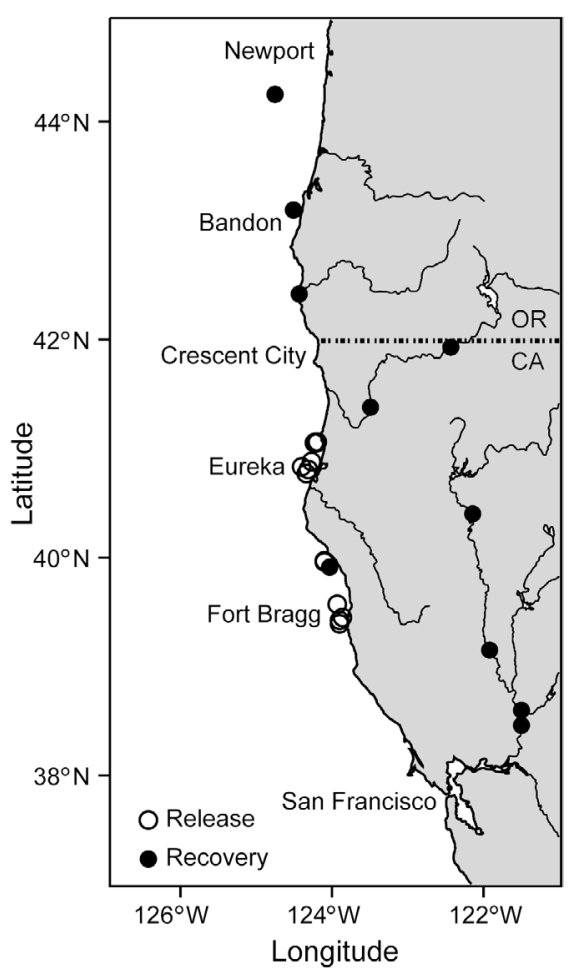

Fig 1. Study area with release and recapture positions

time period of marine residence to focus on interannual variation in habitat use during a period that was common to the available tags. The marine data spanned the time of release to either recapture at sea or to the day prior to river entry. River entry was identified by an abrupt decrease in variability of depths and a sharp increase in temperatures recorded by the tags. Autumn was defined as a $90 \mathrm{~d}$ period from 8 August to 6 November. This period is roughly centered on the autumnal equinox, a date when the sun altitude angle (see below) is halfway between its annual maximum and minimum. Periods of marine data during autumn ranged from 3 to $62 \mathrm{~d}$ (Table 1). In 2002, 2 Chinook that were released in early September remained at sea through the following winter and we truncated the data from those 2 tags on 6 November 2002 (Table 1).

Salmon are suspected of responding to light for both foraging and navigation (Hasler 1971, Friedland et al. 2001). Therefore, we expected that daily patterns of habitat use may have been influenced by both daily and seasonal cycles in ambient light levels. We converted each time observation to a measure of the sun altitude angle, the number of degrees above the horizon, henceforth referred to as the sun angle. This transformation accounts for the changes in day length that occurred while fish were at liberty and also provides a diel index of light availability. Sun angles were calculated for all observations using a general release location for each year. In 2000 and 2002, all releases occurred near Eureka, CA (Table 1) and we used a single, central location $\left(41^{\circ} \mathrm{N}, 124.3^{\circ} \mathrm{W}\right)$ for estimating the sun angles for all fish in those years. For 2003, we used a release location near Fort Bragg, $\mathrm{CA}\left(39.5^{\circ} \mathrm{N}, 123.9^{\circ} \mathrm{W}\right)$. All sun angles $>0$ (above the horizon) were considered daytime observations, while all sun angles $\leq 0$ (below the horizon) were considered nighttime observations. All nighttime sun angles were set to 0 for analysis.

Table 1. Oncorhynchus tshawytscha. Individual release and recapture information. The number of autumn days in the ocean begins on either the release date or 9 August if released earlier and ends on either the ocean recapture (O) or river entry (R) date. In 2 cases, the record was truncated (T) to end on 6 November. For 1 tag (615), the pressure sensor failed (F) at sea and we only include data prior to the malfunction. Release locations refer to the nearest town. Recovery information is approximate and indicates the nearest river or town reported at the time of recapture

\begin{tabular}{|c|c|c|c|c|c|c|c|c|}
\hline \multirow{2}{*}{$\begin{array}{l}\text { Tag } \\
\text { ID }\end{array}$} & \multirow{2}{*}{$\begin{array}{l}\text { Release date } \\
\text { (mo/d/yr) }\end{array}$} & \multirow{2}{*}{$\begin{array}{c}\text { Ocean } \\
\text { days }\end{array}$} & \multicolumn{3}{|c|}{ _ Release } & \multicolumn{3}{|c|}{ Recapture } \\
\hline & & & Location & $\begin{array}{l}\text { Latitude } \\
\left({ }^{\circ} \mathrm{N}\right)\end{array}$ & $\begin{array}{l}\text { Longitude } \\
\left({ }^{\circ} \mathrm{W}\right)\end{array}$ & Location & $\begin{array}{c}\text { Latitude } \\
\left({ }^{\circ} \mathrm{N}\right)\end{array}$ & $\begin{array}{l}\text { Longitude } \\
\left({ }^{\circ} \mathrm{W}\right)\end{array}$ \\
\hline 287 & $8 / 31 / 2000$ & $12(\mathrm{R})$ & Eureka, CA & 41.05 & 124.23 & Sacramento River, CA & 38.60 & 121.50 \\
\hline 290 & $8 / 22 / 2000$ & $12(\mathrm{R})$ & Eureka, CA & 41.06 & 124.19 & Klamath River, CA & 41.38 & 123.49 \\
\hline 291 & $8 / 19 / 2000$ & $45(\mathrm{O})$ & Eureka, CA & 41.05 & 124.20 & Bandon, OR & 43.19 & 124.51 \\
\hline 303 & $8 / 17 / 2000$ & $19(\mathrm{R})$ & Eureka, CA & 41.06 & 124.21 & Rogue River, OR & 42.42 & 124.43 \\
\hline 304 & $8 / 16 / 2000$ & $12(\mathrm{R})$ & Eureka, CA & 41.06 & 124.20 & Klamath River, CA & 41.93 & 122.43 \\
\hline 1226 & $9 / 5 / 2002$ & $62(\mathrm{~T})$ & Eureka, CA & 40.77 & 124.34 & Ft. Bragg, CA & 39.43 & 123.85 \\
\hline 1229 & $9 / 12 / 2002$ & $55(\mathrm{~T})$ & Eureka, CA & 40.88 & 124.27 & Ft. Bragg, CA & 39.43 & 123.85 \\
\hline 1238 & $7 / 24 / 2002$ & 46 (R) & Eureka, CA & 40.83 & 124.40 & Rogue River, OR & 42.42 & 124.43 \\
\hline 1254 & $9 / 10 / 2002$ & $19(\mathrm{R})$ & Eureka, CA & 40.81 & 124.31 & American River, CA & 38.60 & 121.50 \\
\hline 606 & $9 / 5 / 2003$ & $23(\mathrm{R})$ & Fort Bragg, CA & 39.96 & 124.10 & Sacramento River, CA & 39.15 & 121.92 \\
\hline 615 & $9 / 5 / 2003$ & $18(\mathrm{~F})$ & Fort Bragg, CA & 39.97 & 124.10 & Sacramento River, CA & 38.46 & 121.50 \\
\hline 712 & $7 / 8 / 2003$ & $28(\mathrm{R})$ & Fort Bragg, CA & 39.42 & 123.90 & Sacramento River, CA & 40.40 & 122.14 \\
\hline 717 & $7 / 9 / 2003$ & $3(\mathrm{O})$ & Fort Bragg, CA & 39.45 & 123.86 & Shelter Cove, CA & 39.91 & 124.03 \\
\hline 1793 & $8 / 5 / 2003$ & $53(\mathrm{O})$ & Fort Bragg, CA & 39.57 & 123.93 & Newport, OR & 44.25 & 124.75 \\
\hline 1941 & $8 / 21 / 2003$ & 39 (R) & Fort Bragg, CA & 39.39 & 123.90 & American River, CA & 38.60 & 121.50 \\
\hline
\end{tabular}


We used a cluster analysis to identify habitats from the archival-tag data. The clustering algorithm, called 'partitioning around medoids' and implemented as the function clara in S-Plus ${ }^{\circledR}$ (Kaufmann \& Rousseeuw 1990, Insightful 2001), assigns each multivariate observation to exactly 1 cluster. Clusters are formed in an iterative process and observations are assigned to clusters by minimizing an objective function $(\Omega)$ that sums dissimilarities $(d)$ between each observation (i) and its nearest medoid $\left(m_{i}\right)$ :

$$
\Omega=\sum_{i} d\left(i, m_{i}\right)
$$

We computed dissimilarities as euclidean distances and treated the multivariate records of depth, temperature and sun angle from our archival tags as observations. When is minimized, observations within a cluster are generally more similar to each other than to observations in other clusters and, therefore, we interpreted the clusters as specific habitats defined by different combinations of depths, temperatures and sun angles.

It is important to comment on 2 aspects of our cluster analyses. First, crisp clustering methods like the one we used require the analyst to specify the number of clusters, $k$. In general, however, $\Omega$ decreases as $k$ increases and, therefore, a strategy for balancing decreases in dissimilarity with decreases in parsimony is useful. One method of identifying an appropriate number of clusters is to compare average 'silhouette widths' over a range of $k$ values (Insightful 2001). Silhouette widths describe how well an observation can be classified by the cluster to which it is assigned; when the average of these widths is large, the clustering generally classifies the observations well. We considered the silhouette approach but found it difficult to identify an appropriate number of clusters for our habitat data. As an alternative to the silhouette approach, we penalized the objective function. We computed $\Omega$ with $k=\{2,3, \ldots, 12\}$ and selected the clustering that minimized $\Omega+2 k$. Our penalty on $\Omega$ is arbitrary but we found that it provided less equivocal results (in terms of identifying an optimal value of $k$ ) than the silhouette approach. The second point for comment is that measurement units can strongly affect clustering algorithms, especially those based on euclidean distance. In general, the variable with the highest variance will have the largest impact on the cluster definitions. This can be overcome by standardizing the observations but, in our case, this also caused difficulty. Depth and temperature are negatively correlated, causing habitat definitions to be confounded (e.g. in 1 analysis a habitat might be defined as 'deep' and in a second analysis it might be 'cold'). When we standardized our data prior to clustering, this confounding was exacerbated. Standardizing the observations also made it difficult to characterize habitats in general terms because cluster definitions were usually not determined by simple differences in depth, sun angle or temperature. We chose to cluster the data on their original scales of measurement. Our clusters were, therefore, more likely to be defined first by differences in depth, then by differences in sun angle and finally by differences in temperature. In this context, habitat definitions that depend on temperature would indicate strong signals in the data.

We characterized the habitats according to the range of depths, temperatures and sun angles within each cluster. Our characterizations were based on simple phrases such as 'shallow habitat' or 'deep habitat'. To distinguish between day and night habitats, we assumed that habitats with a median sun angle approximately equal to 0 identified a predominantly night time habitat. We then compared the habitat definitions across years and computed the proportion of time spent in each habitat during each year. We used nonparametric ANOVA on ranked data to test for different patterns of habitat use across years.

Finally, we compared the temperature distributions of salmon with sea-surface temperatures (SST) and subsurface temperatures along the coast for time periods during autumn. We present mean SST images for August 2000, 2002 and 2003 that were prepared from individual satellite images. To allow for adequate discrimination of cloud and ocean surfaces, we only used daytime images. We used data from 3 satellites (NOAA-14, NOAA-16 and NOAA-17) with random errors of 0.5 to $0.8^{\circ} \mathrm{C}$ (Walton et al. 1998) and biases of up to $0.2^{\circ} \mathrm{C}$ ( $\mathrm{Li}$ et al. 2001). Subsurface temperature data were collected during US Global Ocean Ecosystems Dynamics (GLOBEC) cruises at standard oceanographic stations along $41.9^{\circ} \mathrm{N}$ latitude on 10 September 2000, 30 September to 1 October 2002 and 28 to 29 September 2003.

We considered 2 descriptions of 'available' habitat: one based on the definition of Essential Fish Habitat as identified in the Pacific Coast Salmon Plan (available at www.pcouncil.org/salmon/salfmp.html) and accepted by the Pacific Fisheries Management Council (PFMC), and one based on the temperature data collected by our archival tags. For areas off the coasts of California (north of Point Conception), Oregon and Washington, the PFMC identifies essential Chinook habitat as all marine waters within the Exclusive Economic Zone (EEZ). Our first description of available habitat, therefore, included all waters both within the EEZ and within the geographic range over which our tags were recovered (from around Newport, OR, in the north to around San Francisco, CA, in the south). We developed a second description of available habitat by estimating the 0.1th and 99.9th quantiles of the distribution of all autumn temperatures recorded by our archival tags. 
We then described available habitat as all waters both within the geographic range over which our tags were recovered and within the temperature range of the estimated quantiles. We used both habitat descriptions to identify available habitat at the surface and we used the temperature-based description to identify available habitat at depth.

\section{RESULTS}

On average, Chinook used waters that were about $10^{\circ} \mathrm{C}$; and temperatures between 9 and $12^{\circ} \mathrm{C}$ encompassed most thermal experiences (Fig. 2A). Some fish consistently used a narrow temperature range (e.g. tag numbers 1226 and 1793), while others used a broad range of temperature (e.g. tag numbers 291 and 303).
The average depth used by all Chinook was $50 \mathrm{~m}$. Some fish were surface-oriented (e.g. tag numbers 290 and 304), while others used deeper waters more consistently (e.g. tag numbers 1793 and 1941, Fig. 2B). Generally, those fish with the longest ocean residence time (e.g. 291, 1226, 1229 and 1793, Table 1) had the deepest distributions (Fig. 2). Fish length at the time of release was not correlated with mean depth $(r=0.03)$ or mean temperature $(\mathrm{r}=-0.01)$ use.

Diel differences in temperature and depth use were not consistent among individuals or years during autumn. Some individuals used colder, deeper waters at night (e.g. tag numbers 287, 303 and 1229), while others used warmer, shallower waters at night (e.g. tag numbers 290, 1238 and 712). Some individuals used similar depths and temperatures during the night and day (e.g. tag numbers 291, 1793 and 1254). Non-parametric, 3-way ANOVA revealed that the variation in temperature and depth use explained by differences among individuals was greater than that explained by differences among years and time of day. We did not test specific hypotheses about the significance of any differences due to individual, annual or diel variation because of strong auto-correlation in the temperature and depth time series.

A time series plot of the depths used by 2 Chinook (e.g. tag numbers 291 and 1238) demonstrate the range of diel vertical movements commonly observed in the individual records (Fig. 3). Vertical movements in excess of $150 \mathrm{~m}$ occurred both during the day and night but the deepest dives typically occurred at night. Switches between the daytime use of shallower waters to the daytime use of deep water were common (Fig. 3A). Other fish showed more consistent patterns of diel behavior (Fig. 3B). In general, however, the short term diel patterns present in the tag data were not sufficiently consistent to produce a distinct pattern over the full time span of the data (Fig. 2).

Four clusters described the habitats used by Chinook in both 2000 and 2002, and 5 described those used in 2003. The first 3 clusters for all years have similar characteristics (Fig. 4). The first cluster for each year was defined by surface water observations that were centered around $10 \mathrm{~m}$ in
Fig. 2. Oncorhynchus tshawytscha. (A) Diel distributions of temperature and (B) depths experienced by tagged Chinook salmon during the autumns of 2000 (tag numbers 287, 290, 291, 303 and 304), 2002 (tag numbers 1226, 1229, 1238 and 1254) and 2003 (tag numbers 606, 615, 712, 717, 1793 and 1941). Medians for day $(\mathrm{O})$ and night $(\bullet)$, and the corresponding interquartile ranges (一) are plotted 


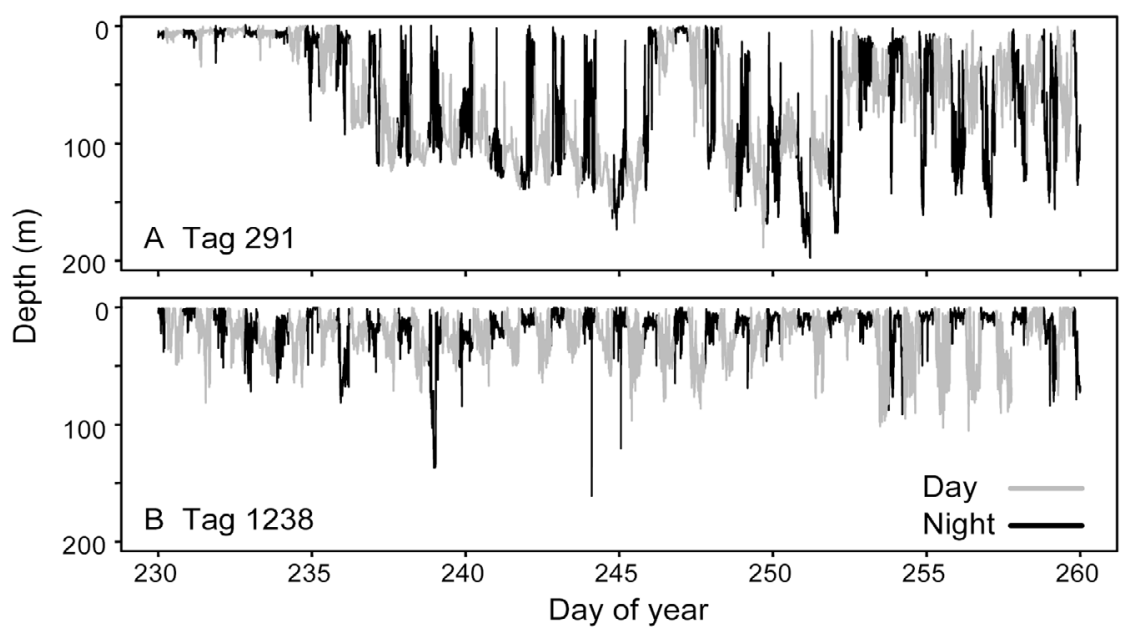

Fig. 3. Oncorhynchus tshawytscha. Diel variation in depth use over $30 \mathrm{~d}$ for $(\mathrm{A})$ tag number 291 and (B) tag number 1238. Chinook with tag numbers 291 and 1238 were released in 2000 and 2002, respectively

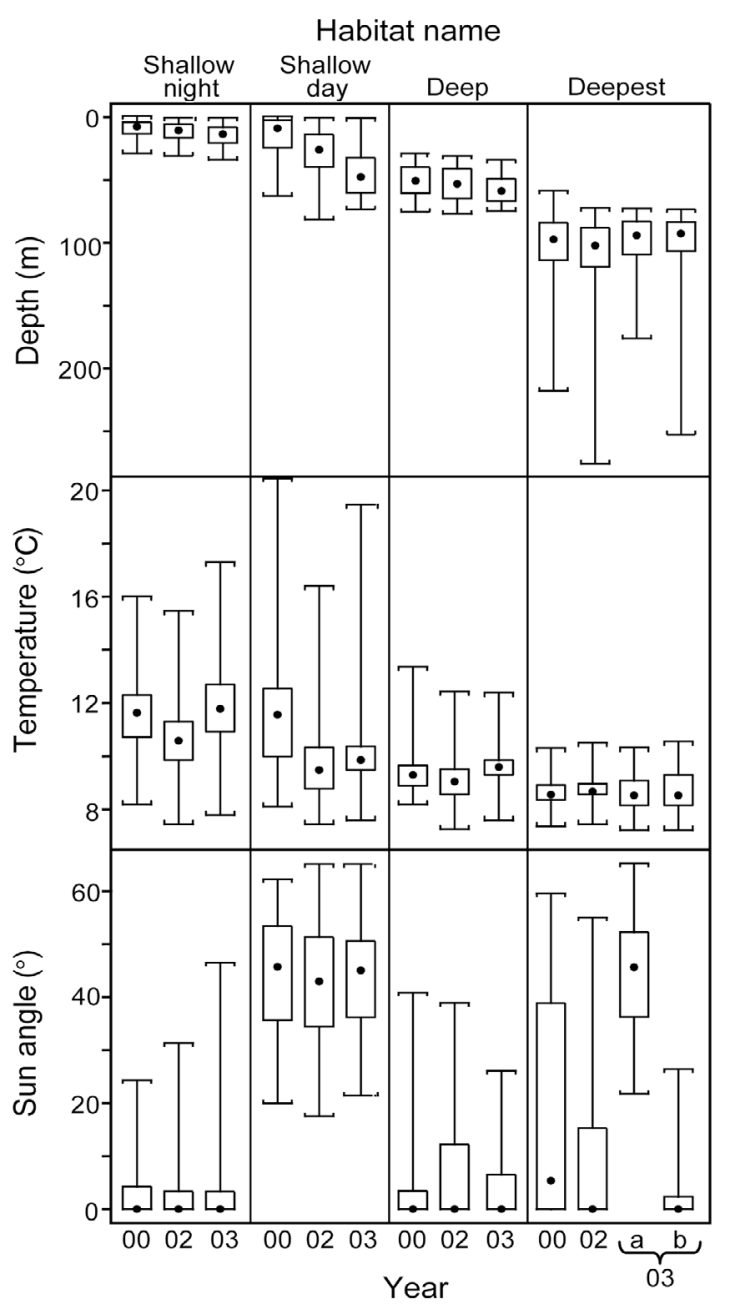

Fig. 4. Oncorhynchus tshawytscha. Distributions of temperatures, depths and sun angles for each cluster from each year. The cluster analyses identified 4 habitats for the 2000 and 2002 data sets. The 2003 data set had 5 clusters, with 2 'deepest' habitats that were distinguished by day (a) and night (b). Each boxplot illustrates the median $(\bullet)$, interquartile range $(\square)$ and range (-) for each measurement variable depth and sun angles that were centered on $0^{\circ}$. The second cluster was defined by depths that extended from the surface to $80 \mathrm{~m}$, included a broad range of temperatures and was used when the sun was more than $20^{\circ}$ above the horizon. During autumn, and at the northern latitudes used here, sun angles greater than $20^{\circ}$ correspond to daylight hours between approximately $07: 30$ and 17:15 $\mathrm{h}$. The third cluster from all years was centered near $55 \mathrm{~m}$, included no depths shallower than $30 \mathrm{~m}$ and was used primarily during the night. The depth and temperature distributions for both the fourth and fifth clusters in 2003 match those from the fourth clusters in 2000 and 2002, but are differentiated by a day-night split (Fig. 4). The final cluster(s) for all years was/were centered around $100 \mathrm{~m}$ in depth, ranged from about 60 to $280 \mathrm{~m}$, had the narrowest and coldest temperature distributions, and were used during all times of the day. The temperature distributions for all clusters overlapped but variation in temperatures tended to decrease with depth. Similar to individual temperature use, the 9 to $12^{\circ} \mathrm{C}$ temperature range encompasses the main temperatures included in the first 3 habitats and represents the upper range of temperatures in the fourth habitat. Temperature and depth were negatively correlated in all tag records $(\mathrm{r}<$ -0.7 , see Fig. 7).

We named the autumn habitats by considering the depth distributions in each cluster and the times of day that those depths were used (Fig. 4). The overlap in temperature across the clusters precluded habitat identification based on temperature differences. Based on the ranges of depths and sun angles in each cluster (Fig. 4), we respectively named the first 3 habitats for all years 'shallow night', 'shallow day' and 'deep'. For 2000 and 2002, the fourth habitat was named 'deepest'. In 2003, the fourth and fifth habitats were named 'deepest day' and 'deepest night'. Nevertheless, given that the deepest habitats in 2000 and 2002 were used at all times of the 
day, we combined the deepest day and deepest night habitats from 2003 to facilitate comparisons across years. To assess individual habitat use in 2003, however, we retained all 5 original habitats for 2003.

On average, patterns of habitat use were similar across years. In each year, the proportions of time
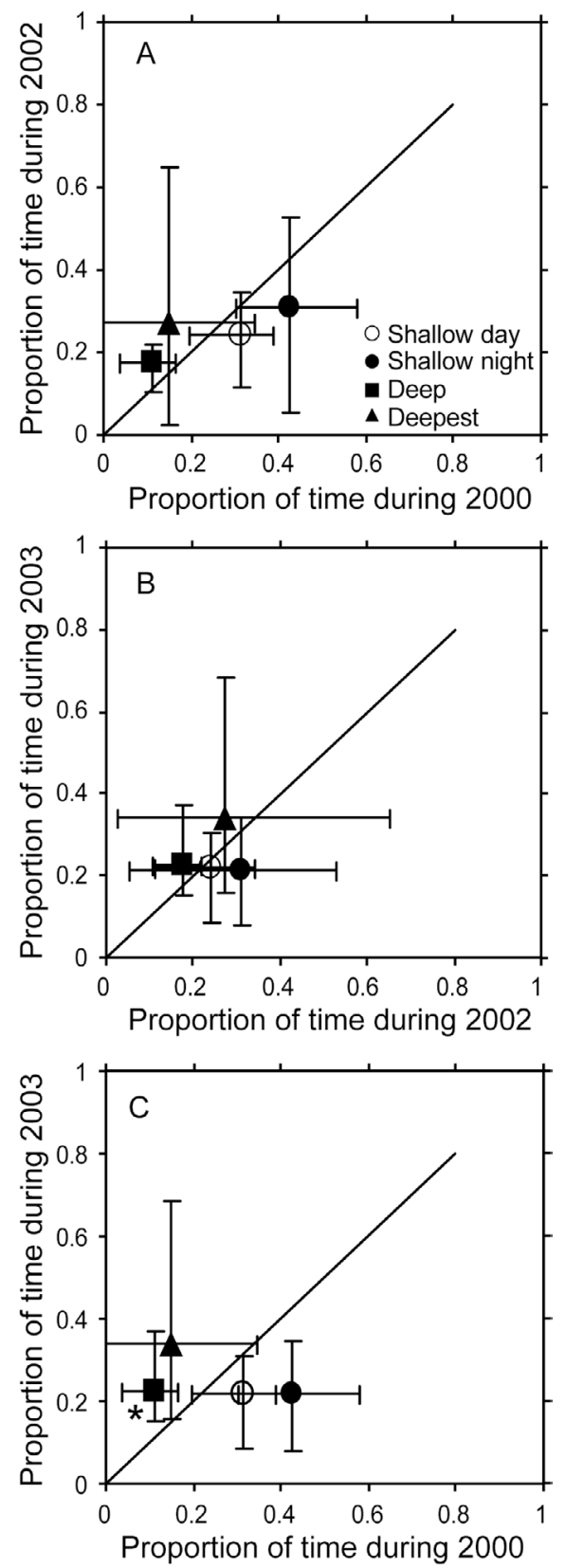

Fig. 5. Oncorhynchus tshawytscha. Interannual comparisons of the proportions of time spent in each habitat. The deepest day and deepest night habitats from 2003 have been combined to represent a single deepest habitat. Significant interannual differences in average proportions of time spent in each habitat are indicated by *. The 1:1 line is drawn for reference spent in the shallow night, shallow day and deepest habitats were not significantly different (ANOVA, $\mathrm{df}=12, F<2.67, \mathrm{p}>0.1$ for each year, Fig. 5). In pairwise comparisons between 2000 and 2002, and between 2002 and 2003, the average proportions of time spent in each habitat were similar (Fig. 5A,B). One difference in annual habitat use occurred between 2000 and 2003; the deep habitat was used more frequently in 2003 than in 2000 (Tukey test, $q=4.1$, p < 0.05, Fig. 5C).

Within years, individual patterns of habitat use varied widely (Fig. 6). Use of the shallow habitats was common to all fish and the shallow night habitat was typically used more often than the shallow day habitat. Use of the deepest habitats varied substantially among individuals (Fig. 6), ranging from infrequent (e.g. tag
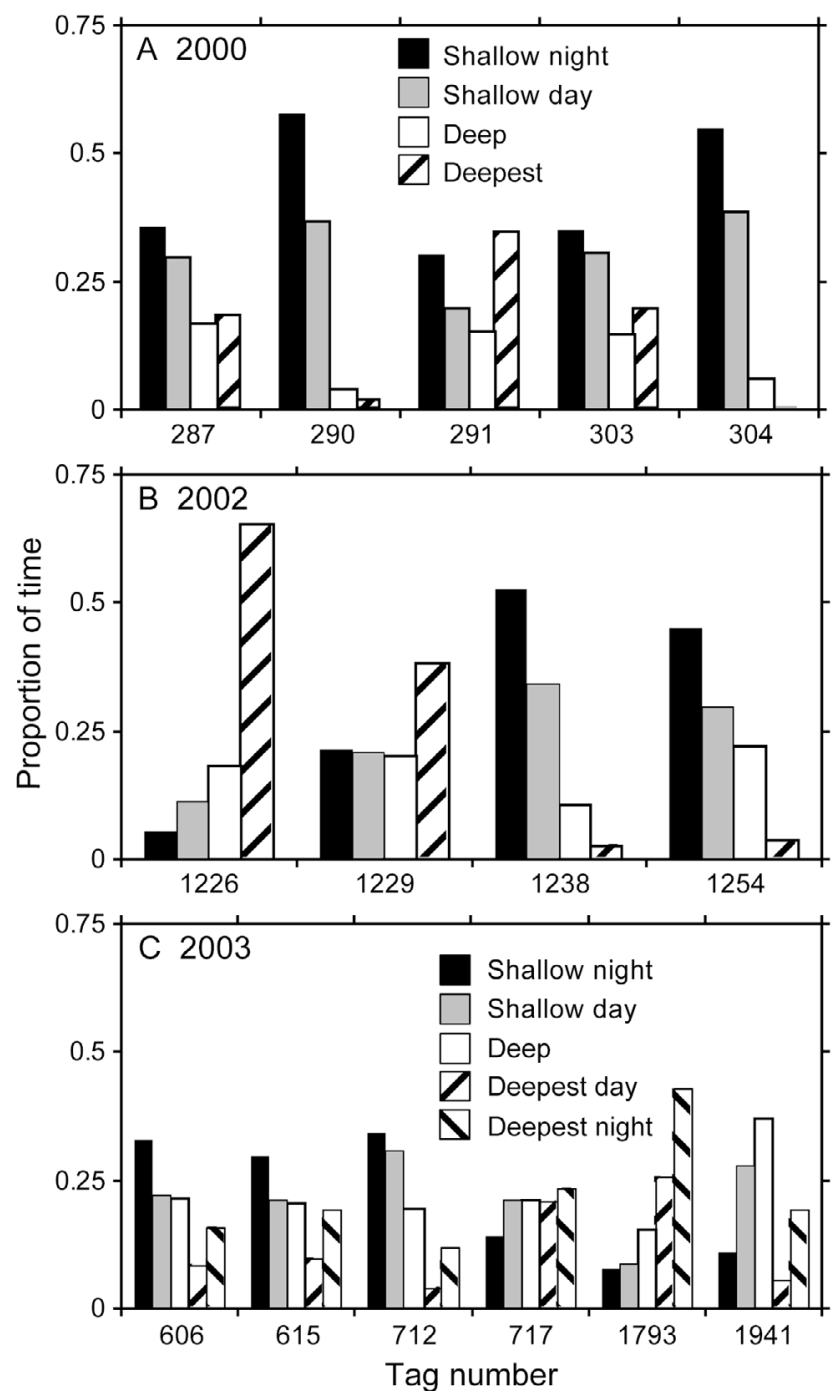

Fig. 6. Oncorhynchus tshawytscha. Proportions of time spent in each habitat by individual Chinook 
numbers 290, 304 and 1238) to predominant (e.g. tag numbers 1226 and 1793). Individual use of ocean habitats also corresponded with the location of recapture. In most cases, fish that were recovered in rivers used the 2 shallow habitats most commonly (Table 1, Fig. 6). The fish carrying tag number 1941, which used the deep habitat most often and was captured in 2003, was the single exception to this pattern. The deepest habi- tat was most commonly used by Chinook that were recaptured at sea or that remained at sea beyond autumn (Table 1, Fig. 6). The average depth used by fish recaptured in the ocean (66 m) was about twice the average depth used by fish that were recaptured in rivers (Student's $t$-test, $\mathrm{df}=13, t=4.13, \mathrm{p}<0.01$ ).

Chinook appeared to use water between 9 and $12{ }^{\circ} \mathrm{C}$ more frequently than might be expected given the
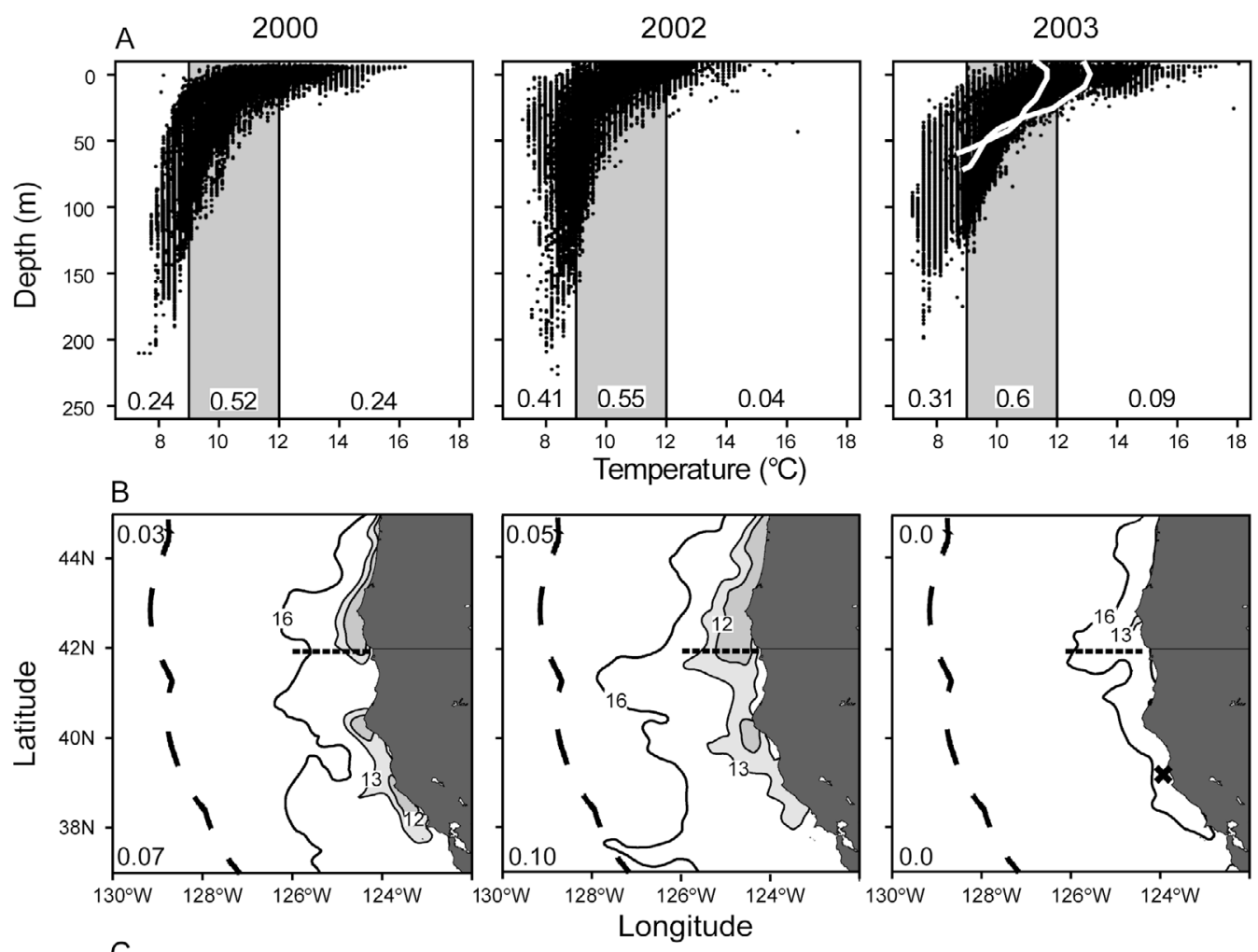

C
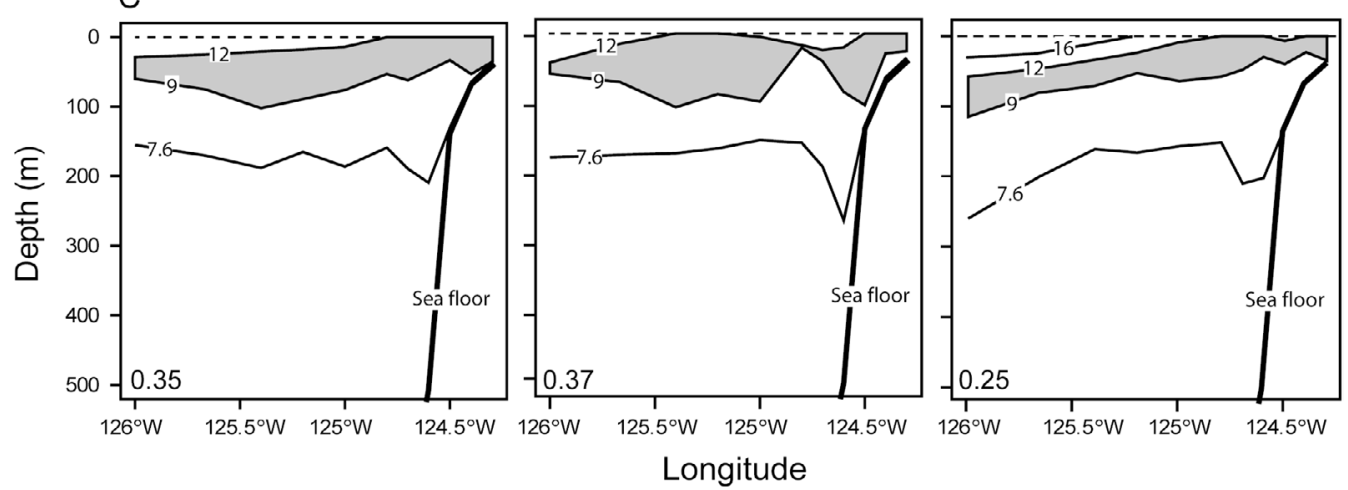

Fig. 7.Oncorhynchus tshawytscha. (A) Temperature/depth profiles from all tags for each year. The white lines in 2003 are temperature/depth profiles that were recorded independently at the location ( $\boldsymbol{x}_{;}$panel B) and time prior to the release of 2 Chinook (tags 1793 and 1941). The shaded area highlights the observations between 9 and $12^{\circ} \mathrm{C}$. The proportion of time spent in each thermal range is indicated in each panel. (B) Sea-surface temperature maps with 12,13 and $16^{\circ} \mathrm{C}$ isotherms. The dashed line is the $200 \mathrm{n}$ mile boundary of the US Exclusive Economic Zone (EEZ), the current definition of essential Chinook habitat. The proportion of surface area containing temperatures $<12^{\circ} \mathrm{C}$ within the EEZ is listed in the upper left corner. The proportion of surface area containing temperatures $<12^{\circ} \mathrm{C}$ within the $16^{\circ} \mathrm{C}$ isotherm is indicated in the lower left corner of each panel. The dashed line indicates the position of the US GLOBEC transect at $41.9^{\circ} \mathrm{N}$. (C) Subsurface isotherms at $41.9^{\circ} \mathrm{N}$. The proportion of 9 and $12^{\circ} \mathrm{C}$ subsurface water between 7.6 and $16^{\circ} \mathrm{C}$ (or surface waters) is indicated in the lower left corner of each panel 
availability of water in this temperature range. Chinook used water in the 9 to $12^{\circ} \mathrm{C}$ range at least $52 \%$ of the time (Fig. 7A). At the surface, the area of water in this temperature range was variable and accounted for less than $5 \%$ of the available habitat when availability was described by the boundary of the EEZ (Fig. 7B). In August 2003, coastal surface waters tended to be warmer than in previous years and may be related to the more consistent use of deep habitats by Chinook in 2003 relative to other years (Fig. 6). The 0.1th and 99.9th quantiles of all temperatures recorded by our tags were, respectively, 7.6 and $16^{\circ} \mathrm{C}$, and when available surface habitat was described by the these quantiles, waters in the 9 to $12^{\circ} \mathrm{C}$ range represented less than $10 \%$ of the surface area. Given the sampling error associated with the satellite images of SST, we included the $13^{\circ} \mathrm{C}$ isotherm as an alternative upper boundary to the possible area of Chinook habitat. This more than doubled the likely surface area used by Chinook but waters in the 9 to $13^{\circ} \mathrm{C}$ range remained less than 14 and $26 \%$ of the available habitat when availability was, respectively, described by the EEZ and the 99.9th quantile of all observed temperatures. Variation in the extent of subsurface habitats also varied among years. For each snapshot of subsurface conditions along the transect at $41.9^{\circ} \mathrm{N}$, the cross-sectional area of water in the 9 to $12^{\circ} \mathrm{C}$ range represented between 25 and $37 \%$ of the available habitat when availability was described by the temperature quantiles (Fig. 7C). As with the SSTs, warmer water was closer to the coast in 2003 than in other years.

\section{DISCUSSION}

Our primary objective was to determine whether individual Chinook salmon use the ocean in similar ways. On an individual level, use of the ocean environment appears quite variable at any given time. The cluster analyses were useful for revealing this variability by summarizing both the timing of habitat use and the amount of time spent in different habitat types for each individual. Broadly viewed, the cluster-based habitat definitions support the hypothesis that a single, generally defined condition is essential for Chinook that are distributed along the coasts of California and Oregon during autumn. This essential condition is defined by temperature; during autumn, Chinook use habitats that are about 9 to $12^{\circ} \mathrm{C}$. This conclusion is based on 5 lines of evidence. First, the range of most temperatures experienced by all individuals was relatively narrow and around 9 to $12^{\circ} \mathrm{C}$. Second, across years, the habitats defined by our cluster analyses were similar. Third, the thermal characteristics of these habitats overlapped the 9 to $12^{\circ} \mathrm{C}$ range considerably. Fourth, the average pro- portions of time that Chinook spent in these habitats were similar across years and, regardless of the habitat definitions, Chinook used 9 to $12^{\circ} \mathrm{C}$ water at least $50 \%$ of the time. Finally, the extent of 9 to $12^{\circ} \mathrm{C}$ water within the range of coastal waters suggests that Chinook use this habitat more frequently than might be expected if usage was based on availability alone.

A growing body of evidence links salmon production to thermal conditions in the coastal ocean (e.g. Cole 1999, Mueter et al. 2002a,b, Friedland et al. 2003) and lends support to the hypothesis that temperatures define essential salmon habitat. Temperatures constrain the distribution of salmon in the subarctic Pacific where the ranges of different species are sharply delimited by small differences in temperature (Welch et al. 1995). In coastal areas, a similar situation seems evident and our analyses suggest that, during autumn, the volume of water with temperatures from about 9 to $12^{\circ} \mathrm{C}$ may provide a useful rule of thumb for defining the overall availability of habitat for Chinook off the coasts of California and Oregon. The aerial estimates of sea surface temperatures and cross-sectional estimates of subsurface temperatures from coastal transects do suggest substantial variation in the availability of water temperatures that Chinook use most commonly during autumn. To better understand oceanographic effects on the distribution and dynamics of salmon populations, an assessment of how that volume of water changes through time appears useful.

Our rule of thumb for identifying essential habitat corresponds to temperature associations of Chinook caught in coastal (Fisher \& Pearcy 1995) and open (Major et al. 1978) ocean habitats, and is similar to that used by fishermen. In fact, 2 independent temperature profiles measured at the times and locations where 2 Chinook were captured and released onboard a commercial salmon trolling vessel in July and August of 2003 overlap the 9 to $12^{\circ} \mathrm{C}$ habitat (Fig. 7A). However, whether this essential temperature condition indicates preferential selection of specific thermal habitats or reflects temperature-based physiological limitations for Chinook is not clear. In either case, we speculate that 9 to $12^{\circ} \mathrm{C}$ temperatures may provide conditions favorable for growth and maturation of Chinook, and provide a target for both management and fishing opportunities.

Despite its primacy, however, temperature only provides a rough guess as to where an individual Chinook might be found. Our cluster analyses illustrated that both the depths used by Chinook and the times those depths were occupied varies widely among individuals. Candy \& Quinn (1999) also made observations that suggest widely varying individual behaviors within a common background temperature of 9 to $12^{\circ} \mathrm{C}$. Variability in the use of depth likely derives from many 
factors that are not commonly measured by archival tags. Such factors may include physical variables such as salinity or dissolved oxygen concentrations. Strong coastal currents, upwelling and eddies all contribute substantial, 3-dimensional variability to oceanographic conditions off the coasts of California and Oregon (Lynn et al. 2003), and Chinook may alter their position in the water column according to the evolution and movement of suitable habitats. Furthermore, bottom depth may ultimately constrain depth use. Nearshore environments, where Chinook are typically found (Fisher \& Pearcy 1995), are relatively shallow. Thus, a shallow orientation may occur because the deepest habitats are simply not available.

Biological factors may be other sources of variability in depth use by Chinook (Candy \& Quinn 1999) and it is useful to consider such factors in the context of an individual's state of maturation. The ages of fish used in this study are not known but were presumably a mix of immature (those that wintered or were recaptured at sea) and maturing individuals (those caught in rivers). Immature fish may use the coastal ocean as foraging grounds and a migration corridor but maturing fish must also search for their natal streams. Habitat requirements for these types of behavior would presumably be different. The depths at which Chinook forage and migrate may be determined by responses to the distribution of predators and prey (Candy \& Quinn 1999), while the depths used by homing fish may be determined more by visual and olfactory cues (Dittman \& Quinn 1996). Our finding that surface-oriented Chinook were mostly recaptured in rivers supports the suggestion that different life-history stages use depth in the coastal ocean differently (Healy 1991).

The differences in depth use by different life-history stages raise the question about the timing of, and causes for, such a switch in habitat use. Our data indicate that a change in the depths used by Chinook, as they transition from the ocean to the river, probably occurred before the beginning of autumn. For example, the Chinook carrying tag number 1238 maintained a surface orientation for a full month prior to river entry, with no clear switch in diving behavior as the time of river entry neared (Fig. 3B). Thus, the question of what cues caused this difference in depth use remains and provides a link back to the problem of unobserved physical variables. Regardless, we believe that thermal conditions provide the best indicator of Chinook habitat in the coastal ocean; we observed individuals at potentially different stages of maturity using the same temperatures.

The results of our work give additional perspective to expectations generated from previous studies in which researchers examined short-term patterns of habitat use by Chinook. Candy \& Quinn (1999) observed diel differences in the depths used by Chinook but Ogura \& Ishida (1995) did not. Although this difference might be explained by differences in study area (Candy \& Quinn 1999 made observations in Johnstone Strait and Ogura \& Ishida [1995] made observations in the central Bering Sea), our results suggest that this difference may be related to the time period over which the 2 sets of observations were made. Both sets of authors tracked individuals, via ultrasonic telemetry, for periods less than about $4 \mathrm{~d}$. In contrast, our records of vertical behavior span periods of up to $62 \mathrm{~d}$. We found that individuals exhibit diel patterns of depth use that last for a few days and then reverse or break down altogether. Thus, the longer-term perspective provided by our archival-tag data suggests that Chinook are plastic in their use of the water column.

An important limitation of this study derives from a lack of understanding of (1) whether and (2) how the tagging procedure and the external tags influenced the behavior of Chinook at sea. Two previous studies on salmonids have reported on apparent tag-induced behaviors, each reporting different time periods over which the tagging effect was evident. Candy \& Quinn (1999) considered the tagging effect on adult Chinook to last up to $8 \mathrm{~h}$. Walker et al. (2000), whose tag attachment method we used, considered tagging effects that lasted from 4 to $21 \mathrm{~d}$. For each of our tags, we plotted a time series of the daily proportions of time spent in each of the habitats defined by the cluster analyses and found no consistent changes (data not shown) in habitat use over the time periods for which tagging effects have been suggested. Additionally, visual inspections of the temperature and depth time series suggested that the post-release patterns of temperature and depth use reoccurred in later time periods, and were not consistent among individuals. A confounding problem for addressing tagging effects, as discussed by Walker et al (2000), lies in the absence of data on the behavior of untagged fish at sea. Our study also suffers from this shortcoming. We stress that while tagging effects are not readily apparent in our data, they may exist. We may not have been able to identify tagging effects because the Chinook we studied were released into the coastal ocean. Relatively high variability in the structure of the coastal ocean may mask tagging effects that might be detected in less variable environments like the open ocean, where Walker et al. (2001) made observations.

To summarize, we reiterate 2 important conclusions. First, individual use of coastal habitats was variable and represented a high degree of behavioral plasticity by Chinook. This finding provides opportunities for further research on whether and to what extent variation in patterns of habitat use among individuals derives from identifiable sources. Second, despite sub- 
stantial individual variation, 1 essential condition was experienced by 15 different Chinook during 3 different years. Chinook that are distributed along the coasts of California and Oregon during autumn used water that is between 9 and $12^{\circ} \mathrm{C}$ at least $52 \%$ of the time. Availability of that thermal habitat, based on SSTs, represented between 0 and $3 \%$ of the currently defined Essential Fish Habitat for Chinook and between 0 and $10 \%$ of the surface area within the range of temperatures experienced by the Chinook we tagged. Our estimates of the availability of subsurface habitat, 24 to $37 \%$, were also less than the proportions of time Chinook spent in water of 9 to $12^{\circ} \mathrm{C}$. The consistency in the use of this thermal habitat lends support to hypotheses linking salmon population dynamics to ocean temperature regimes (e.g. Cole 2000, Mueter et al. 2002a). Further monitoring of thermal habitats, both surface and subsurface, relevant to Chinook salmon may be useful for assessing the extent and quality of conditions most likely to sustain their populations.

Acknowledgements. The authors thank the many people involved in the tagging efforts over the last $4 \mathrm{yr}$, particularly those who provided fishing vessels, attached tags or voluntarily returned tags. CoastWatch Satellite data were acquired from the NOAA Comprehensive Large Array Stewardship System. The satellite data were provided by D. Foley, courtesy of the National Weather Service and NOAA CoastWatch Program. Subsurface temperature data were provided courtesy of J. Fleishbein and the US GLOBEC NEP program. Comments and suggestions by S. Hayes, A. Hobday and J. Polovina, and 3 anonymous referees improved this manuscript. This work was partially supported by SaltonstallKennedy Grant funds.

\section{LITERATURE CITED}

Beamish RJ, Neville CEM, Cass AJ (1997) Production of Fraser River sockeye salmon (Oncorhynchus nerka) in relation to decadal-scale changes in climate and the ocean. Can J Fish Aquat Sci 54:543-554

Bisbal GA, McConnaha WE (1998) Consideration of ocean conditions in the management of salmon. Can J Fish Aquat Sci 55:2178-2186

Boehlert GW (1997) Application of acoustic and archival tags to assess estuarine, nearshore, and offshore habitat utilization and movement of salmonids. NOAA Tech Memo 236

Candy JR, Quinn TP (1999) Behavior of adult Chinook salmon (Oncorhynchus tshawytscha) in British Columbia coastal waters determined from ultrasonic telemetry. Can J Zool 77:1161-1169

Cole J (2000) Coastal sea surface temperature and coho salmon production off the north-west United States. Fish Oceanogr 9:1-16

Dittman AH, Quinn TP (1996) Homing in Pacific salmon: mechanisms and ecological basis. J Exp Biol 199:83-91

Fisher JP, Pearcy WG (1995) Distribution, migration, and growth of juvenile chinook salmon, Oncorhynchus tshawytscha, off Oregon and Washington. Fish Bull 93: 274-289
Friedland KD, Walker RV, Davis ND, Myers KW, Boehlert GW, Urawa S, Ueno Y (2001) Open-ocean orientation and return migration routes of chum salmon based on temperature data from data storage tags. Mar Ecol Prog Ser 216: $235-252$

Friedland KD, Reddin DG, Castonguay M (2003) Ocean thermal conditions in the post-smolt nursery of North American Atlantic salmon. ICES J Mar Sci 60:343-355

Gargett AE (1997) The optimal stability 'window': a mechanism underlying decadal fluctuations in North Pacific salmon stocks. Fish Oceanogr 6:109-117

Hasler AD (1971) Orientation and fish migration. In: Hoar WS, Randall DJ (eds) Fish physiology, Vol VI. Environmental relations and behavior. Academic Press, New York, p 429-510

Healey MC (1991) Life history of Chinook salmon. In: Groot C, Margolis L (eds) Pacific salmon life histories. University of British Columbia Press, Vancouver

Hobday AJ, Boehlert GW (2001) The role of coastal ocean variation in spatial and temporal patterns in survival and size of coho salmon (Oncorhynchus kisutch). Can J Fish Aquat Sci 58:2021-2036

Insightful (2001) S-PLUS 6 for Windows guide to statistics, Vol 2. Insightful Corporation, Seattle, WA

Kaufmann L, Rousseeuw PJ (1990) Finding groups in data: an introduction to cluster analysis. John Wiley \& Sons, New York

Li X, Pichel W, Clemente-Colón P, Krasnopolsky V, Sapper J (2001) Validation of coastal sea and lake surface temperature measurements derived from NOAA/AVHRR Data. Int J Remote Sens 22:1285-1303

Lynn RJ, Bograd SJ, Chereskin TK, Huyer A (2003) Seasonal renewal of the California current: the spring transition off California. J Geophys Res C 108(8):3279, doi:10.1029/2003 JC001787

Major RL, Ito J, Ito S, Godfrey H (1978) Distribution and origin of chinook salmon (Oncorhynchus tshawytscha) in offshore waters of the North Pacific Ocean. Int North Pac Fish Comm Bull 38:1-54

Mantua NJ, Hare SR, Zhang Y, Wallace JM, Francis RC (1997) A Pacific interdecadal climate oscillation with impacts on salmon production. Bull Am Meteorol Soc 78:1069-1079

Mueter FJ, Peterman RM, Pyper BJ (2002a) Opposite effects of ocean temperature on survival rates of 120 stocks of Pacific salmon (Oncorhynchus spp.) in northern and southern areas. Can J Fish Aquat Sci 59:456-463

Mueter FJ, Ware DM, Peterman RM (2002b) Spatial correlation patterns in coastal environmental variables and survival rates of salmon in the north-east Pacific Ocean. Fish Oceanogr 11:205-218

Myers, KW, Aydin KY, Walker RV, Fowler S, Dahlberg ML (1996) Known ocean ranges of stocks of Pacific salmon and steelhead as shown by tagging experiments, 1956-1995. Document 192, North Pacific Anadromous Fish Commission, Vancouver

Ogura M, Ishida Y (1995) Homing behavior and vertical movements of four species of Pacific salmon (Oncorhynchus spp.) in the central Bering Sea. Can J Fish Aquat Sci 52:532-540

Orsi JA, Wertheimer AC (1995) Marine vertical distribution of juvenile Chinook and coho salmon in southeastern Alaska. Trans Am Fish Soc 124:159-169

Pacific Fishery Management Council (2003) Preseason report. I Stock abundance analysis for 2003 ocean salmon fisheries. Pacific Fishery Management Council, Portland, OR 
Pearcy WG (1992) Ocean ecology of north Pacific salmonids. Washington Seagrant Program, Seattle, WA

Walker RV, Myers KW, Davis ND, Aydin KY and 6 others (2000) Diurnal variation in thermal environment experienced by salmonids in the North Pacific as indicated by data storage tags. Fish Oceanogr 9:171-186

Walton CC, Pichel WG, Sapper JF, May DA (1998) The development and operational application of nonlinear algorithms for the measurement of sea surface temperatures

Editorial responsibility: Otto Kinne (Editor-in-Chief), Oldendorf/Luhe, Germany with the NOAA polar-orbiting environmental satellites. J Geophys Res C 103(12):27999-28012

Welch DW, Chigirinsky AI, Ishida Y (1995) Upper thermal limits on the oceanic distribution of Pacific salmon (Oncorhynchus spp.) in the spring. Can J Fish Aquat Sci 52: 489-503

Welch DW, Boehlert GW, Ward BR (2003) POST-the Pacific Ocean salmon tracking project. Oceanol Acta 25:243-253

Submitted: January 20, 2004; Accepted: August 12, 2004 Proofs received from author(s): January 7, 2005 